Molecules 2002, 7, 601-617

molecules

ISSN 1420-3049

http://www.mdpi.org

\title{
Towards Highly Activating Leaving Groups: Studies on the Preparation of Some Halogenated Alkyl Sulfonates ${ }^{\dagger}$
}

\section{Thomas Netscher* and Patrick Bohrer}

Research and Development, Roche Vitamins Ltd, CH-4070 Basel, Switzerland. Tel. (+41) 61688

6755, Fax (+41) 616872201

* Author to whom correspondence should be addressed; e-mail: thomas.netscher@roche.com

Received: 16 May 2002; in revised form: 13 August 2002 / Accepted: 24 August 2002 / Published: 31

August 2002

${ }^{+}$Dedicated to Professor em. Dr. mult. Dr. h.c. mult. Alois Haas on occasion of his $70^{\text {th }}$ birthday and in acknowledgement of his contributions to fluorine and sulfur chemistry

\begin{abstract}
The trichloromethylsulfonyl-, dichloromethylsulfonyl-, chlorosulfonyl-, and fluorosulfonyl esters of a neopentyl-type alcohol have been prepared via sulfonylation or sulfinylation followed by oxidation. The preparative usefulness and potential of the transformations are discussed.
\end{abstract}

Keywords: Alkylation reagents, $\mathrm{S}_{\mathrm{N}} 2$ substitution reactions, steric hindrance, sulfonic esters, sulfur-oxygen bond cleavage.

\section{Introduction}

Nucleophilic substitution reactions at $\mathrm{sp}^{3}$-carbon centers are among the most important transformations in organic chemistry. The nucleofugality of leaving groups used in organic synthesis, measured by the rates of solvolysis, covers a range of at least fourteen orders of magnitude $[1,2]$. Despite this large variety, there is still a need to improve the efficiency of many $\mathrm{S}_{\mathrm{N}} 2$-type synthetic operations. Since halides used as (soft) alkylating reagents often tend to undergo elimination reactions on treatment with (hard) nucleophiles like e.g. alcoholates, esters of oxo-acids are widely applied alternatives. While moderately reactive phosphate esters play a crucial role in biological systems, alkyl 
(as also alkenyl and aryl) esters of sulfonic acids in particular are indispensable for preparative and mechanistic organic chemistry.

The proper choice of reagents and conditions for nucleophilic substitution reactions deserves, however, careful attention to the steric and electronic requirements of both the attacking nucleophile and the electrophile. If alkyl sulfonates are used, several side-reactions can substantially limit the value of the transformation. One major problem often encountered is unwanted sulfur-oxygen bond scission. As a typical example, $\mathrm{S}_{\mathrm{N}} 2$ reaction by $\mathrm{Nu}^{-}$at the saturated carbon atom of alkyl $p$-toluenesulfonates 1 (Scheme 1, route a) has to compete with backside attack of the sulfur atom (route b) or sulfene formation if the nucleophile behaves as a strong base $\mathrm{B}^{-}$(route c), resulting in formation of alcohol 3 besides alkylated product 2 .
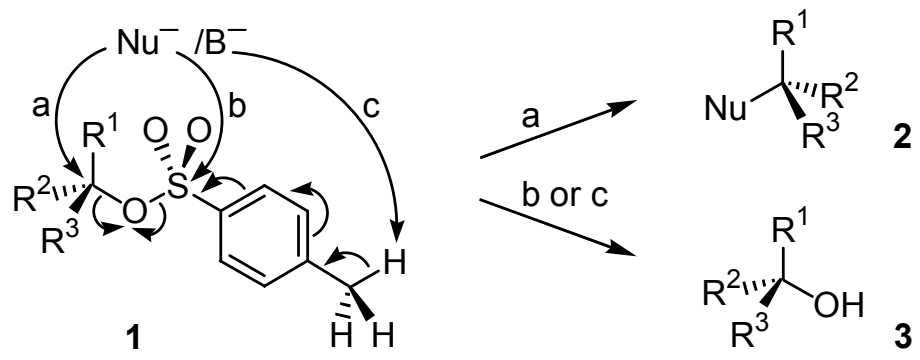

\section{Scheme 1}

Forced by the necessity to improve some demanding $\mathrm{S}_{\mathrm{N}} 2$ substitution reactions of highly functionalized or unfavorably substituted substrates, we directed considerable efforts to the evaluation and development of more advanced sulfonyl functionalities. In this program two key aspects had to be considered: 1) $S$-substitution should be retarded effectively by steric shielding, and 2) nucleofugality should be reasonably high, i.e. the reactivity of the esters should be in the range between trifluoroethanesulfonates (tresylates 4) [3] and perfluoroalkylsulfonates (triflates 5, nonaflates 6) [2]. The first aim could be reached with tert-butylsulfonates 7 [4,5] which were, however, expected as being slightly less nucleofugic than methanesulfonates (mesylates $\mathbf{8}$ ) or tosylates $\mathbf{9}$. Both requirements are fulfilled by the 2,2,2-trifluoro-1,1-diphenylethanesulfonates (TDE-sulfonates 10) which can, therefore, be applied in a preparatively useful manner [4-6]. With regard to the present paper, it is noteworthy that for the preparation of the corresponding reagent a sulfur functionality had been introduced to a fluorine containing precursor, while the opposite strategy (fluorination of a sulfur compound) was unsuccessful [7-12].

\begin{tabular}{|c|c|c|c|c|c|c|c|c|c|c|}
\hline & & 4 & 5 & 6 & 7 & 8 & 9 & 10 & 11 & 1213 \\
\hline S-Y & $Y$ & $\mathrm{CH}_{2} \mathrm{CF}_{3}$ & $\mathrm{CF}_{3}$ & $\mathrm{C}_{4} \mathrm{~F}_{9}$ & $\mathrm{C}\left(\mathrm{CH}_{3}\right)_{3}$ & $\mathrm{CH}_{3}$ & $\mathrm{C}_{6} \mathrm{H}_{4} \mathrm{CH}_{3}-(4)$ & $\mathrm{C}\left(\mathrm{C}_{6} \mathrm{H}_{5}\right)_{2} \mathrm{CF}_{3}$ & $\mathrm{CCl}_{3}$ & $\mathrm{~F} \mathrm{Cl}$ \\
\hline
\end{tabular}


Regarding highly activating leaving groups, there was at that stage still a gap in the arsenal of preparatively applicable sulfonic esters between (substituted) tresylates and perfluoroalkylsulfonates. In addition to the lack of suitable reagents in this range, it is of common knowledge that the use of the latter esters is subject to certain limitations. Often problems arise from the instability of commonly used triflates 5, which result in difficulties either in storage or purity or purification of these highly reactive intermediates. Even analysis of such products deserves special attention [13]. Moreover, the preparation of triflates is sometimes far from trivial. During the esterification of sterically congested alcohols with triflic anhydride, the formation of sulfur(IV) esters (sulfinates) has been detected, depending on the base and conditions applied [14]. If pyridine is used as a (standard) base and solvent, pyridinium salts may be formed due to the high reactivity of triflates [15].

With regard to the complications mentioned, we would, therefore, in this contribution like to report on some findings during our trials to prepare alkyl esters of perhalogenated sulfonic acids, in particular trichloromethyl-, fluoro-, and chlorosulfonic acid (11-13). The application of these esters in nucleophilic substitution reactions had, to our knowledge, not been studied systematically so far. When reviewing the literature we had to learn that even their preparation from the corresponding alcohols is documented only fragmentarily.

\section{Results and Discussion}

As a starting material for the preparation of representative perhalogenated esters we chose the oxaneopentylic alcohol 14 by the following reasons: 14 is easily accessible from the commercially available carboxylic acid Trolox ${ }^{\mathrm{TM}}$. Resulting from our activities in the field of vitamin E synthesis [16], a large variety of oxo-esters had already been prepared, most of them (including perfluoroalkylsulfonates) being easily isolable, nicely crystalline, and possessing considerable thermal stability. In addition, NMR, MS, UV, TLC, HPLC, and GC or SFC [13] can be used as analytical methods, and samples of various structurally related by-products were available in our laboratory. Most importantly, esters 15 are ideal test systems for evaluation of the efficiency of steric shielding about the sulfonate functionality: Since the oxa-neopentylic center is not easily accessible to the nucleophile, these esters are more susceptible to sulfur attack than normal primary alkyl sulfonates. In addition, E2-elimination of the sulfonic acid is not possible, due to the lack of $\beta$-hydrogens.

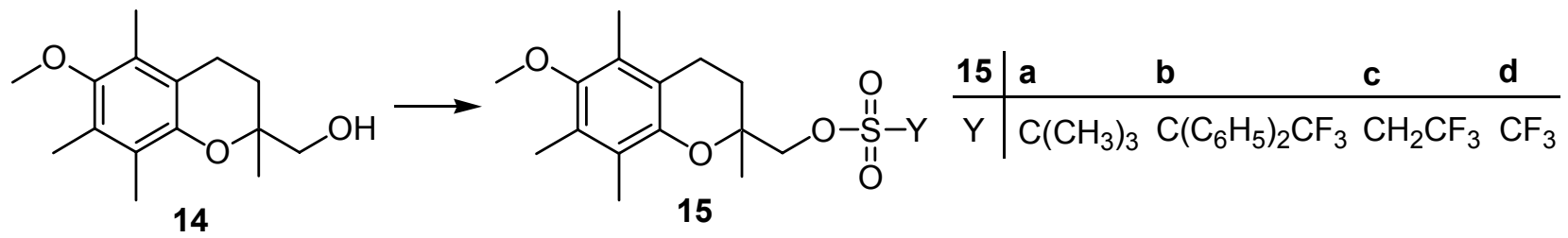

Beside tert-butylsulfonate 15a, TDE-sulfonate 15b, tresylate 15c, and triflate $15 \mathbf{d}$ prepared by standard and improved procedures $[2,3,5,14]$, the nonaflate 15e was also synthesized for comparison (Scheme 2). During preparation of 15e another limitation became apparent. In contrast to examples 
reported in the literature [17], alcohol $\mathbf{1 4}$ did not react with (commercially available) nonafluorobutanesulfonyl fluoride under mild conditions (room temp. $\rightarrow$ refluxing $\mathrm{CH}_{2} \mathrm{Cl}_{2}$, 2,6lutidine). After solvent exchange to 2,6-lutidine and prolonged heating (up to $90^{\circ} \mathrm{C}$ bath temp. for several days), alcohol 14 (59\%) was re-isolated by chromatography along with decomposition products. Nonaflate 15e could be obtained in $82 \%$ yield by use of nonaflyl anhydride which had, however, first to be prepared from potassium nonafluorobutanesulfonate $[2,18,19]$ due to lack of commercial availability.
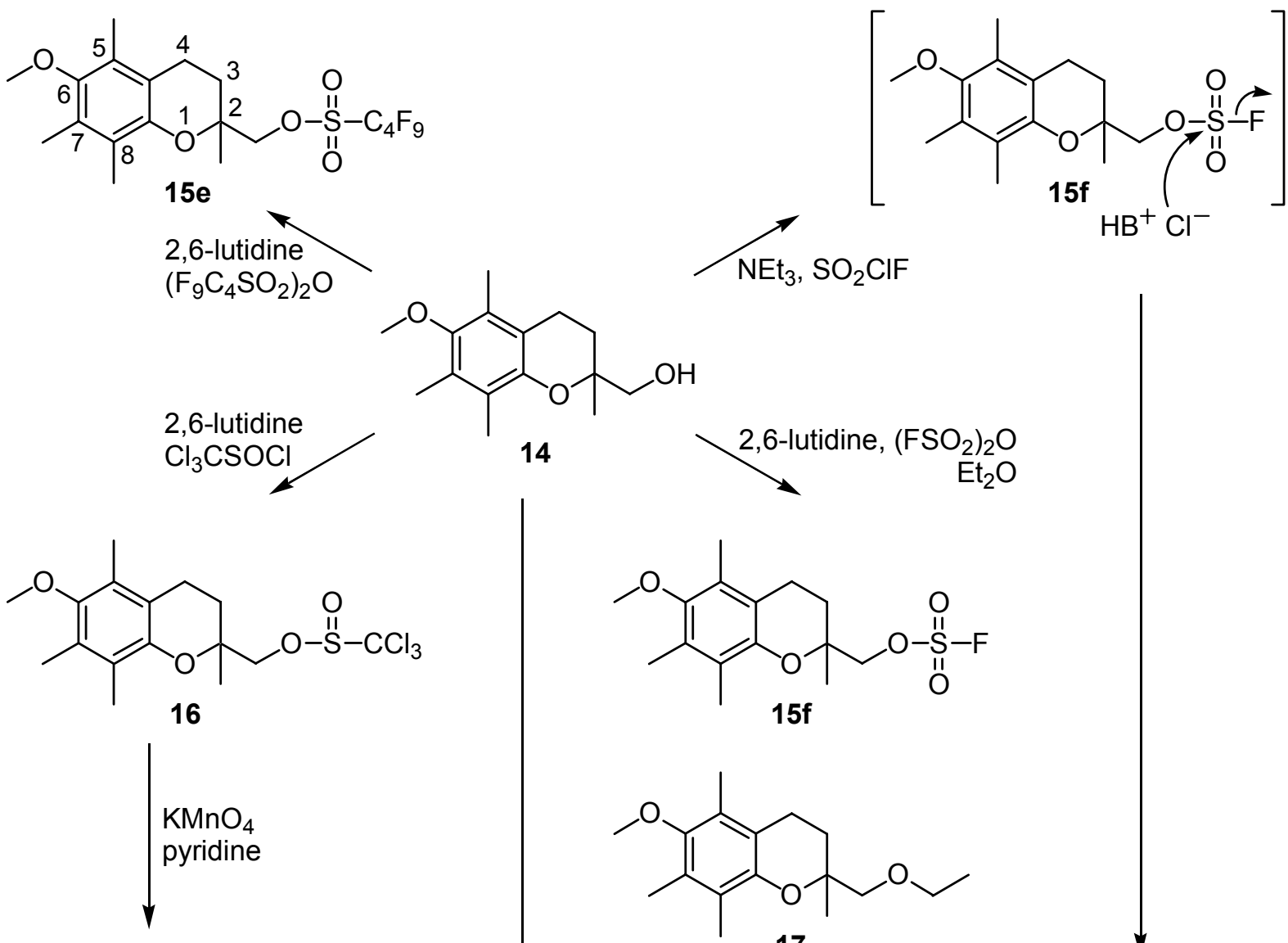<smiles>COc1c(C)c(C)c2c(c1C)CC[C@@](C)(COS(=O)(=O)Cl)O2</smiles><smiles>CCCS(=O)(=O)OCC1(C)CCc2c(C)c(OC)c(C)c(C)c2O1</smiles>
$15 i$

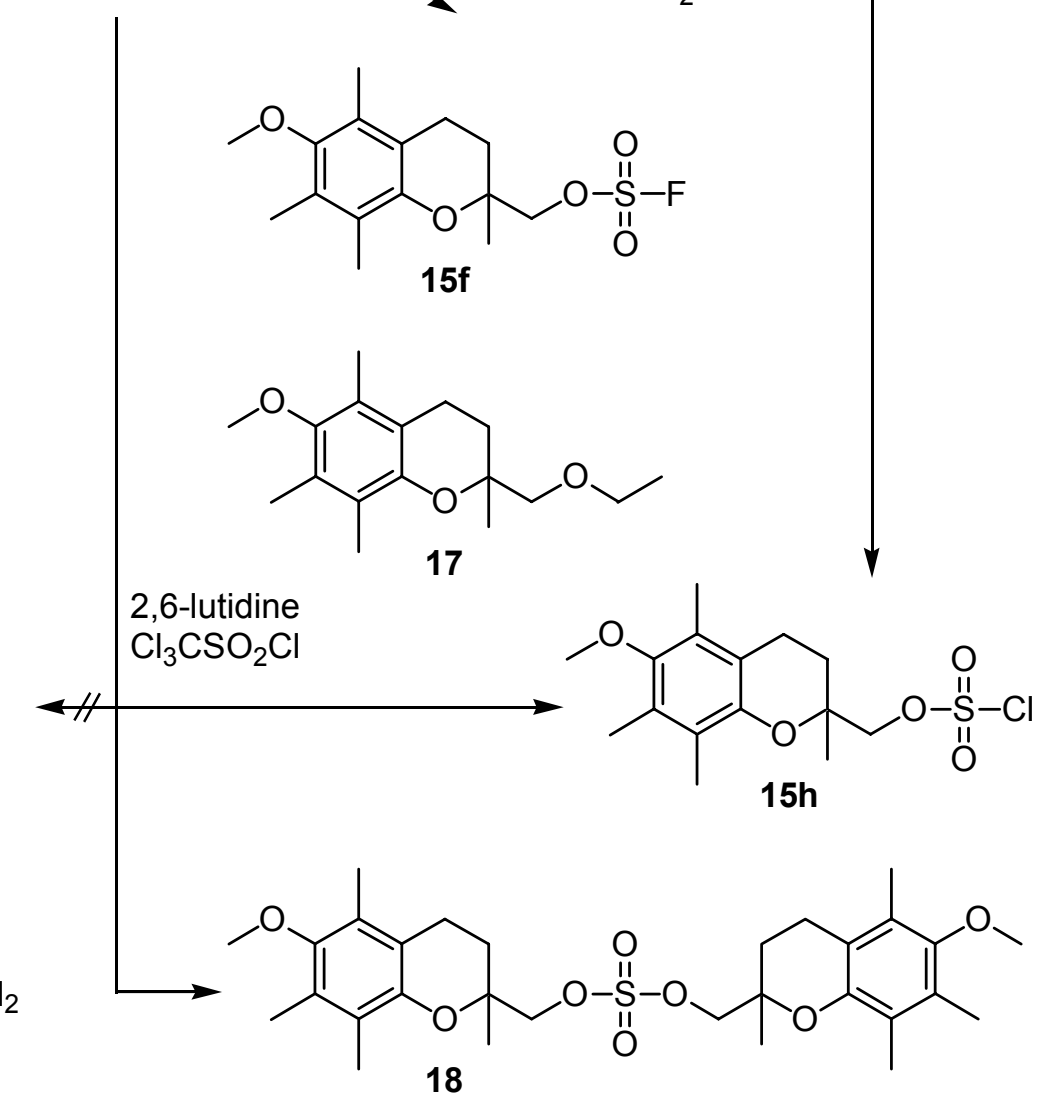

Scheme 2 
Our next aim was to gain access to trichloromethanesulfonates 11. Such esters seemed to be highly attractive electrophiles in $\mathrm{S}_{\mathrm{N}}$ 2-type reactions possessing the properties mentioned above; the three chlorine atoms should, on the one hand, strongly activate due to their powerful electron-withdrawing abilities. The trichloromethyl group on the other hand was hoped to behave like a tert-butyl moiety in which the chlorine atoms would mimic the methyl groups of about same size, thus preventing sulfuroxygen bond cleavage by steric hindrance. The bulkiness of the backbone should considerably influence the tendency of the sulfur(VI) atom to be attacked by a nucleophile, since this process most likely involves a trigonal bipyramidal transition state with linear arrangement of incoming nucleophile and departing leaving group, as indicated by kinetic investigations on sulfonyl chlorides [20].

The direct esterification of hydroxy compounds with the sulfonyl chloride seems to be limited to polyhalogenated alcohols [21,22], while normal alkyl alcohols are unreactive [23]. Therefore, in compliance with our expectation from earlier experiences [24], treatment of alcohol 14 with trichloromethanesulfonyl chloride in presence of 2,6-lutidine as a base did not result in formation of trichloromethanesulfonate 15g (Scheme 2). Instead, only starting alcohol was detected by TLC after 75 $\mathrm{h}$ in refluxing $\mathrm{CH}_{2} \mathrm{Cl}_{2}$. This can be interpreted as an indication for the validity of the concept of steric shielding, as explained above. The formation of chlorosulfonate $15 \mathrm{~h}$ as the main product ( $36 \%$ isolated after chromatography and crystallization; 8\% bissulfonate 18) under forced conditions (refluxing THF, $18 \mathrm{~h}$ ) may be explained by attack of the sulfonyl sulfur atom by the alcohol from the less hindered side. The substitution of the $\mathrm{CCl}_{3}^{-}$group instead of chloride has its precedents in preparative applications like the haloform reaction or the generation of dichlorocarbene from methyl trichloromethanesulfinate or trichloromethanesulfonyl chloride [25].

An alternative general strategy for the synthesis of sulfonates from alcohols is the preparation of sulfur(II) or sulfur(IV) intermediates (sulfenates, sulfinates), followed by their oxidation to the sulfur(VI) compounds. The sulfinate $\mathbf{1 6}$ was obtained smoothly by esterification of alcohol 14 with the sulfinyl chloride (2,6-lutidine, $\mathrm{CH}_{2} \mathrm{Cl}_{2}, 30 \mathrm{~min}$., room temp.) as a nicely crystalline material (92\% after simple recrystallisation from pentane). A more rewarding transformation was the oxidation to the sulfonate: the resistance of trichloromethyl sulfinates (and structurally related compounds) towards oxidation is known, and has been applied preparatively in the almost quantitative formation of benzyl trichloromethylsulfinates from sulfenate esters and $m$-chloroperbenzoic acid: Even in the presence of a large excess of reagent in refluxing chloroform, no oxidation to the sulfonates was observed [26]. Since in a similar case [24] even treatment with excess trifluoroperacetic acid $\left(\mathrm{CH}_{2} \mathrm{Cl}_{2}\right.$, reflux $)$ and other reagents [27] was unsuccessful, we tested potassium permanganate as a strong oxidant.

In a first experiment, sulfinate $\mathbf{1 6}$ was reacted with two mole equivalents of $\mathrm{KMnO}_{4}$ in a pyridinewater mixture at $0^{\circ} \mathrm{C}$ (Scheme 2). After 15 minutes, starting material had disappeared completely, and three major products could be isolated after quenching with sodium sulfite solution, aqueous work-up, and chromatography. Alcohol 14 (20\%) and the two sulfonates $\mathbf{1 5 g}$ and $\mathbf{1 5 i}$ (14\% yield each) were obtained as crystalline compounds. The somewhat unexpected outcome of this oxidation reaction may be related to experiences from mechanistic studies with di- and trichloromethyl sulfenic and sulfinic derivatives: It has been stated that enhanced reactivity and participation of the trichloromethyl group in 
solvolytic reactions makes analogies from behavior of "normal" sulfur compounds (e.g. containing the methanesulfenyl vs. trifluoromethanesulfenyl group) questionable [28]. Due to the only partially explored unusual reactivity of such trichloromethyl sulfur compounds, more detailed studies have to be undertaken in order to check the potential of this transformation.

Having enough material for test reactions in hand, we decided to not investigate the mechanism of that reaction and, consequently, did not optimise the conditions for preferred formation of either $\mathbf{1 5 g}$ or 15i. Although the yields of sulfonates $\mathbf{1 5} \mathrm{g}$ and $\mathbf{1 5 i}$ isolated are quite low, this result deserves some special comments regarding preparative applicability of such esters. It is noteworthy that the experiment described is, to the best of our knowledge, the first example for preparation of an alkyl trichloromethanesulfonate on this route starting from an alcohol. In addition to this initial aim, the unexpected formation of dichloromethanesulfonate 15i is even more remarkable: So far the chlorination of chloromethanesulfonates (prepared from chloromethanesulfonyl chloride [29]) with Nchlorosuccinimide in hexamethylphosphoramide is reported as being the preferred method for the synthesis of aryl di- and trichloromethanesulfonates [30]; the scope of its applicability is, however, expected to be limited by the sensitivity of functionalities contained in substrates.

Both trichloromethanesulfonates and dichloromethanesulfonates (like e.g. 15g and 15i) should be (re-)considered as either underutilized old or promising new types of alkylating reagents, since in those esters the sulfonyl sulfur is much less prone to attack by nucleophiles than corresponding methanesulfonates or chloromethanesulfonates [30]. In this context it is important to note that recent work has shown the (mono-) chloromethanesulfonate (monochlate) group as an extremely efficient leaving group in certain rearrangement and substitution reactions [31]. Regarding dichloromethanesulfonates, we did not check whether their preparation is possible by direct esterification of alcohols with dichloromethanesulfonyl chloride (19) [32]. Most likely, this will take place via a base-induced elimination-addition process involving dichlorosulfene (20), as outlined in Scheme 3.

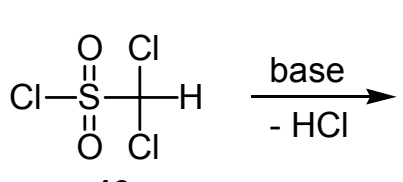

19

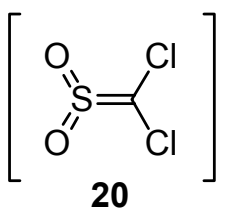

20

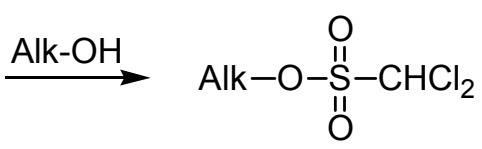

Scheme 3

Furthermore, fluorosulfonates 12 [33] and chlorosulfonates 13 [34] are of particular interest for nucleophilic substitution reactions. Therefore, the preparation of sulfonates $\mathbf{1 5 f}$ and $\mathbf{1 5 h}$ was envisaged (see Scheme 2). According to literature examples [35], alcohol 14 was treated with sulfuryl chloride fluoride $\left(\mathrm{NEt}_{3}, \mathrm{CH}_{2} \mathrm{Cl}_{2},-78^{\circ} \mathrm{C}\right)$. Surprisingly, the chlorosulfonate $\mathbf{1 5 h}$ already found accidentally during attempted synthesis of trichloroderivative 15g, was obtained in high yield. We assume that in this case the intermediately formed fluorosulfonate $\mathbf{1 5 f}$ was transformed to the chlorosulfonate $\mathbf{1 5 h}$ by 
substitution of fluoride by the better nucleophile $\mathrm{Cl}^{-}$[36]. Remarkably, no fluoride at all could be found by microanalysis of the crystalline product isolated in $72 \%$ yield. In this regard it has to be mentioned that chlorosulfonates $\mathbf{1 3}$ can be obtained from alcohols and sulfuryl chloride [34,37]; they have also been used as in-situ generated precursors of imidazole-1-sulfonates (imidazylates) 21 [38]. From an industrial viewpoint, it is noteworthy that a more economical combined use of sulfur dioxide and chlorine gas as a replacement of sulfuryl chloride has been documented [39]. The fluorosulfonate 15f could be synthesized by treatment of alcohol 14 with (toxic) fluorosulfonic anhydride (freshly prepared from fluorosulfonic acid and cyanuric chloride [2,40]) (2,6-lutidine, $\mathrm{Et}_{2} \mathrm{O},-78^{\circ} \mathrm{C} \rightarrow$ room temp., $44 \%$ yield unoptimized). The material isolated contained ca. $4 \%$ of chlorosulfonate $\mathbf{1 5 h}$, according to SFC and microanalysis, which is assumed to have its origin in chlorine-containing byproducts of anhydride preparation. Ethyl ether derivative 17 (6\%) was also isolated, indicating a participation of the diethyl ether solvent in this transformation.

\section{Conclusions and Outlook}

Some per- or polyhalogenated sulfonic esters could be prepared for the first time from a neopentyltype alcohol by sulfonylation or sulfinylation and subsequent oxidation. We are aware of the fact that this report does not provide data of a complete study, and individual transformations described gave only moderate to even low yields. The results presented should, however, help to initiate further detailed investigations towards the development of halogenated sulfonate esters, of which the potential of practical use is essentially unexplored. In initial experiments with nucleophiles, the sulfonic esters prepared showed a behavior quite different from that of conventional sulfonates. Detailed studies of the reactivity of activated sulfonic esters towards various $\mathrm{H-}, \mathrm{C}-, \mathrm{N-}, \mathrm{O}-, \mathrm{Hal}-, \mathrm{P}-$, and $\mathrm{S}$-nucleophiles will be published elsewhere.

\section{Acknowledgements}

We thank Mr. I. Gautschi for experimental assistance, and our colleagues from the Pharmaceuticals Division of F. Hoffmann-La Roche Ltd (NMR, IR, MS, GC/ SFC, and combustion analyses) for their analytical investigations and interpretations.

\section{Experimental}

\section{General}

All reactions were performed under an argon atmosphere. Room temperature was 20 to $22^{\circ} \mathrm{C}$. All reagents and chemicals not mentioned separately were obtained from Fluka or Aldrich, or were technical grade from Roche, and were used without further purification, if not stated individually. Nonafluorobutanesulfonic anhydride was prepared by treatment of potassium nonafluorobutanesulfonate with sulfuric acid/oleum and subsequent dehydration of the sulfonic acid by distillation from 
excess phosphorus pentoxide mixed with Celite ${ }^{\circledR}[2,18,19]$. Fluorosulfonic anhydride was prepared from fluorosulfonic acid and cyanuric chloride [2,40]. Dichloromethane was freshly distilled from $\mathrm{CaH}_{2}$, and THF from Na/benzophenone under argon. For transfer of solvents, reagents (if liquid), or their solutions, syringes, cannulae and rubber septa were used. The reactions were monitored by thin layer chromatography (TLC) using glass plates coated with silica gel $60 \mathrm{~F}_{254}, 0.25 \mathrm{~mm}$ thickness (Merck); spots were visualized by spraying with solutions of $2 \%$ vanillin in ethanol/water/sulfuric acid or ammonium molybdate/cerium sulfate in water/sulfuric acid, and subsequent heating. Flash chromatography was performed using silica gel 60, 0.040-0.063 mm (Merck) under max. 0.2 bar argon pressure. IR spectra were measured with a Nicolet 170-SX FT-IR instrument, values are reported in $\mathrm{cm}^{-1}$. NMR spectra were obtained using Bruker AC-250 and AC-250E spectrometers and were recorded at $250.1 \mathrm{MHz}\left({ }^{1} \mathrm{H}\right)$ and $235.36 \mathrm{MHz}\left({ }^{19} \mathrm{~F}\right)$, respectively, for $\mathrm{CDCl}_{3}$-solutions with tetramethylsilane (TMS) as an internal standard $\left({ }^{1} \mathrm{H}\right)$ or referred to $\mathrm{CFCl}_{3}\left({ }^{19} \mathrm{~F}\right)$; chemical shifts in ppm $(\delta), \mathrm{m}_{\mathrm{c}}$ means centered multiplet, " $\mathrm{t}$ " structured triplet, coupling constants in Hz. EI-MS were obtained with an MS9 instrument (AEI, Manchester, GB); ionisation energy $70 \mathrm{eV}$, temp. of ion source $250^{\circ} \mathrm{C}$; $\mathrm{m} / \mathrm{z}$ values in $\%$, relative to the base peak $(=100 \%)$. Gas chromatographic $(\mathrm{GC})$ analyses were performed using a Dani 3800 instrument with a flame-ionisation detector (FID) and split/splitless injector, 15-m PS-086 column, carrier gas hydrogen, temperature program $50-330^{\circ} \mathrm{C}$, injector temp. $40-300^{\circ} \mathrm{C}$, detector temp. $330^{\circ} \mathrm{C}$, values in area $\%$. Supercritical fluid chromatography (SFC) was performed with a Lee Scientific SFC Model 600 (Dionex, Salt Lake City, UT) and a Carlo Erba model 3000 apparatus equipped with an FID operated at 375 or $325^{\circ} \mathrm{C}$; SFC-grade unmodified carbon dioxide (Messer-Griesheim, Germany) was used as a mobile phase, and time split injections were performed with a Valco C14W high-pressure valve that had a 200-nL loop; injection time was $50 \mathrm{~ms}$; 10-m $\times 50$ $\mu \mathrm{m}$ i.d. and $25-\mathrm{m} \times 100-\mu \mathrm{m}$ fused-silica capillary columns, coated with biphenyl-30 as a stationary phase, and a fused-silica restrictor (Dionex) were used; column temp. $100^{\circ} \mathrm{C}$, if not stated otherwise; density programs $0.2-0.75 \mathrm{~g} \cdot \mathrm{mL}^{-1}$ with a linear ramp at $0.01 \mathrm{~g} \cdot \mathrm{mL}^{-1} \cdot \mathrm{min}^{-1}$ or $0.4-0.75 \mathrm{~g} \cdot \mathrm{mL}^{-1}$ with a linear ramp at $0.005 \mathrm{~g} \cdot \mathrm{mL}^{-1} \cdot \mathrm{min}^{-1}$ (cf. [13]).

\section{Preparation of nonafluorobutanesulfonate $\mathbf{1 5 e}$}

The magnetically stirred solution of alcohol $14(6.01 \mathrm{~g}, 24.0 \mathrm{mmol})$ in freshly distilled $\mathrm{CH}_{2} \mathrm{Cl}_{2}(100$ $\mathrm{mL})$ contained in a $250-\mathrm{mL}$ two-necked round-bottomed flask was cooled to $-78^{\circ} \mathrm{C}(\mathbf{1 4}$ partially crystallized out at this temp.). Then freshly dist. 2,6-lutidine $(5.8 \mathrm{~mL}, 50.0 \mathrm{mmol})$ and, subsequently, nonaflyl anhydride $(28.0 \mathrm{~g}, 48.1 \mathrm{mmol})$ were added in one portion. The cooling bath was removed. While warming up to room temp. the colour of the reaction mixture turned to red. At room temp. total conversion was detected by TLC [1:3 EtOAc/hexane, $\mathrm{R}_{\mathrm{f}}(\mathbf{1 4})$ 0.2, $\mathrm{R}_{\mathrm{f}}(\mathbf{1 5 e})$ 0.5]. The reaction mixture was diluted with $\mathrm{CH}_{2} \mathrm{Cl}_{2}$ and poured on ice/water. The organic layer was washed with sat. $\mathrm{NaHCO}_{3}$ and $\mathrm{NaCl}$ solutions, and dried over $\mathrm{Na}_{2} \mathrm{SO}_{4} / \mathrm{CaCl}_{2}$. Evaporation under reduced pressure at $20^{\circ} \mathrm{C}$ (rotary evaporator; caution: foaming!) gave $16.7 \mathrm{~g}$ crude sulfonate, which was dissolved in $\mathrm{Et}_{2} \mathrm{O}(100 \mathrm{~mL})$ and $\mathrm{CH}_{2} \mathrm{Cl}_{2}(10 \mathrm{~mL})$, treated with active carbon and Speedex, filtered, and evaporated to an easy-to-stir 
slurry. Storage at $-20^{\circ} \mathrm{C}$ overnight gave crystals which were washed with a small amount of $\mathrm{Et}_{2} \mathrm{O}$ and dried under high vacuum (11.34 g). These crystals were dissolved in $\mathrm{Et}_{2} \mathrm{O}(50 \mathrm{~mL})$, and the solution treated with charcoal/Speedex. Dilution of the colourless solution with pentane and concentration by evaporation under reduced pressure at $20^{\circ} \mathrm{C}$ gave a slurry which was stored at $-20^{\circ} \mathrm{C}$ for several hours. Suction filtration and washing with a small amount of pentane yielded $7.65 \mathrm{~g}$ of colourless shiny crystals, which were used for analyses. The mother liquors were collected and chromatographed (200 g $\mathrm{SiO}_{2}$, EtOAc/ hexane 1:19) to give additional $2.82 \mathrm{~g}$ sulfonate; combined yield $82 \%$. An experiment with $\mathrm{Na}_{2} \mathrm{CO}_{3}$ as a base in $\mathrm{CH}_{2} \mathrm{Cl}_{2}\left(-15 \rightarrow 20^{\circ} \mathrm{C}\right)$ [18] gave $32 \%$ 15e after chromatography.

[(RS)-3,4-Dihydro-6-methoxy-2,5,7,8-tetramethyl-2H-1-benzopyran-2-yl]methyl nonafluorobutanesulfonate (15e): M.p. 88-89.5 ${ }^{\circ}$; purity 99.7\% (SFC); ${ }^{1} \mathrm{H}-\mathrm{NMR}: \delta 1.36\left(\mathrm{~s}, \mathrm{C}_{\text {tert }}-\mathrm{CH}_{3}, 3 \mathrm{H}\right), 1.85\left(\mathrm{~m}_{\mathrm{c}}\right.$, $\left.\underline{\mathrm{C}}_{2} \mathrm{CH}_{2} \mathrm{Ar}, 1 \mathrm{H}\right), 1.99\left(\mathrm{~m}_{\mathrm{c}}, \mathrm{C}_{2} \mathrm{CH}_{2} \mathrm{Ar}, 1 \mathrm{H}\right), 2.08$ (s, Ar- $\left.\mathrm{CH}_{3}, 3 \mathrm{H}\right), 2.15$ (s, Ar- $\left.\mathrm{CH}_{3}, 3 \mathrm{H}\right), 2.19$ (s, Ar$\mathrm{CH}_{3}, 3 \mathrm{H}$ ), 2.66 ("t", $\left.\mathrm{CH}_{2} \mathrm{CH}_{2} \mathrm{Ar}, 2 \mathrm{H}, \mathrm{J}=6.9\right), 3.63$ (s, $\left.\mathrm{OCH}_{3}, 3 \mathrm{H}\right), 4.46\left(\mathrm{AB}, \mathrm{CH}_{2} \mathrm{OSO}_{2}, 1 \mathrm{H}, \mathrm{J}=\right.$ 10.1), $4.53\left(\underline{\mathrm{AB}}, \mathrm{CH}_{2} \mathrm{OSO}_{2}, 1 \mathrm{H}, \mathrm{J}=10.1\right) ;{ }^{19} \mathrm{~F}-\mathrm{NMR}: \delta-126.78\left(\mathrm{~m}_{\mathrm{c}}, \mathrm{CF}_{3}-\mathrm{CF}_{2}, 2 \mathrm{~F}\right),-121.86\left(\mathrm{~m}_{\mathrm{c}}\right.$, $\left.\mathrm{CF}_{3}-\mathrm{CF}_{2}-\mathrm{CF}_{2}, 2 \mathrm{~F}\right),-111.20\left(\mathrm{~m}_{\mathrm{c}}, \mathrm{CF}_{3}-\mathrm{CF}_{2}-\mathrm{CF}_{2}-\mathrm{CF}_{2}, 2 \mathrm{~F}\right),-81.18$ (t, $\left.\mathrm{CF}_{3}, 3 \mathrm{~F}\right)$; IR (KBr): 2940, 1466, 1407, 1355, 1299, 1258, 1236, 1200, 1145, 1094, 1040, 1011, 964, 789, 736, 700, 659, 594, $507 \mathrm{~cm}^{-1}$; MS: m/z $532\left(\mathrm{M}^{\bullet+}, 100\right), 517\left(\mathrm{M}^{\bullet+}-15,10\right), 233\left(\mathrm{M}^{\bullet+}-\mathrm{ONf}, 17\right), 232\left(\mathrm{M}^{\bullet+}-\mathrm{HONf}, 15\right), 219$ (32), 217 (42), $179\left(\mathrm{C}_{11} \mathrm{H}_{15} \mathrm{O}_{2}{ }^{++}\right.$, 79); Anal. Calcd. for $\mathrm{C}_{19} \mathrm{H}_{21} \mathrm{~F}_{9} \mathrm{O}_{5} \mathrm{~S}$ (532.41): C 42.86, H 3.98, F 32.11, S 6.02, Found C 42.72, H 4.15, F 32.54, S 5.75.

Esterification of alcohol $\mathbf{1 4}$ with fluorosulfonic anhydride: Formation of fluorosulfonate $\mathbf{1 5 f}$ and ethyl ether 17

In a 100-mL two-necked round-bottomed flask, 2,6-lutidine (1.16 mL, $10.0 \mathrm{mmol})$ was added dropwise at $-78^{\circ} \mathrm{C}$ while stirring to a solution of fluorosulfonic anhydride $(1.68 \mathrm{~g}, 9.2 \mathrm{mmol}$, freshly distilled after treatment with conc. $\mathrm{H}_{2} \mathrm{SO}_{4}$; caution: Highly Toxic!) in $\mathrm{Et}_{2} \mathrm{O}$ (40 mL). Alcohol 14 (1.25 $\mathrm{g}, 5.0 \mathrm{mmol})$ dissolved in $\mathrm{Et}_{2} \mathrm{O}(20 \mathrm{~mL})$ was then added during $5 \mathrm{~min}$. (14 partially crystallized out during this operation). The cooling bath was removed. While warming up to room temperature the mixture became a white suspension. TLC [EtOAc/ hexane $1: 3, R_{f}(\mathbf{1 4}) 0.30, R_{f}(\mathbf{1 7}) 0.80, R_{f}(\mathbf{1 5 f}) 0.58$ ] indicated incomplete conversion. The reaction mixture was poured onto cooled $\left(0^{\circ} \mathrm{C}\right) 2 \mathrm{~N} \mathrm{H}_{2} \mathrm{SO}_{4}$. After separation of the phases, the organic layer was extracted with water, dried, and evaporated to dryness (rotary evaporator, reduced pressure). Filtration of the residue through a pad of silica gel gave $2.246 \mathrm{~g}$ of crude material which was chromatographed $\left(470-\mathrm{mL} \mathrm{SiO}_{2}\right.$ Büchi medium-pressure column, $\mathrm{Et}_{2} \mathrm{O} /$ hexane 1:9). The first fraction contained $88 \mathrm{mg}(6 \%)$ of oily ethyl ether 17 . The second fraction gave $730 \mathrm{mg}$ (44\%) of sulfonate $\mathbf{1 5 f}$ (containing ca. $4 \%$ of chlorosulfonate $\mathbf{1 5 h}$; SFC, microanalysis), which after recrystallization from a small amount of $\mathrm{Et}_{2} \mathrm{O}$ using charcoal afforded $691 \mathrm{mg}(42 \%)$ of colourless solid. 
Rac-(3,4-Dihydro-6-methoxy-2,5,7,8-tetramethyl-2H-1-benzopyran-2-yl)methyl fluorosulfonate (15f). M.p. $69-70^{\circ} \mathrm{C}$; purity $95.8 \% \mathbf{1 5 f}+4.2 \% \mathbf{1 5} \mathbf{h}\left(\mathrm{SFC}\right.$ at $\left.80^{\circ} \mathrm{C}\right), 92.9 \% \mathbf{1 5 f}+3.5 \% \mathbf{1 5 h}\left(\mathrm{SFC}\right.$ at $100^{\circ} \mathrm{C}$; indicating thermal decomposition during analysis [13]); ${ }^{1} \mathrm{H}-\mathrm{NMR}: \delta 1.37\left(\mathrm{~s}, \mathrm{C}_{\text {tert }}-\mathrm{CH}_{3}, 3 \mathrm{H}\right), 1.86\left(\mathrm{~m}_{\mathrm{c}}\right.$, $\left.\mathrm{C}_{2} \mathrm{CH}_{2} \mathrm{Ar}, 1 \mathrm{H}\right), 2.00\left(\mathrm{~m}_{\mathrm{c}}, \mathrm{CH}_{2} \mathrm{CH}_{2} \mathrm{Ar}, 1 \mathrm{H}\right), 2.08$ (s, Ar- $\left.\mathrm{CH}_{3}, 3 \mathrm{H}\right), 2.15$ (s, Ar- $\left.\mathrm{CH}_{3}, 3 \mathrm{H}\right), 2.19$ (s, Ar$\mathrm{CH}_{3}, 3 \mathrm{H}$ ), 2.66 ("t", $\left.\mathrm{CH}_{2} \mathrm{CH}_{2} \mathrm{Ar}, 2 \mathrm{H}, \mathrm{J}=6.9\right), 3.63$ (s, $\left.\mathrm{OCH}_{3}, 3 \mathrm{H}\right), 4.43\left(\mathrm{AB}, \mathrm{CH}_{2} \mathrm{OSO}_{2}, 1 \mathrm{H}, \mathrm{J}=\right.$ 9.9), 4.50 ( $\underline{\mathrm{AB}}, \mathrm{CH}_{2} \mathrm{OSO}_{2}, 1 \mathrm{H}, \mathrm{J}=9.9$ ); IR (KBr): 2941, 1436, 1403, 1302, 1255, 1226, 1178, 1121 , 1089, 1061, 977, 929, 880, 793, 596, $546 \mathrm{~cm}^{-1}$; MS: $332\left(\mathrm{M}^{++}, 100\right), 317\left(\mathrm{M}^{\circ+}-15,19\right), 217(46), 179$ $\left(\mathrm{C}_{11} \mathrm{H}_{15} \mathrm{O}_{2}{ }^{++}, 80\right), 178$ (66); Anal. Calcd. for $\mathrm{C}_{15} \mathrm{H}_{21} \mathrm{FO}_{5} \mathrm{~S}$ (332.39): C 54.20, H 6.37, F 5.72, S 9.65, Found C 54.18, H 6.47, F 5.53, S 9.55, Cl 0.51.

Rac-2-(Ethoxymethyl)-3,4-dihydro-6-methoxy-2,5,7,8-tetramethyl-2H-1-benzopyran (17). Oil; purity 97.9\% (GC); ${ }^{1} \mathrm{H}-\mathrm{NMR}: \delta 1.19\left(\mathrm{t}, \mathrm{CH}_{2}-\mathrm{CH}_{3}, 3 \mathrm{H}, \mathrm{J}=7.0\right), 1.28\left(\mathrm{~s}, \mathrm{C}_{\text {tert }}-\mathrm{CH}_{3}, 3 \mathrm{H}\right), 1.76\left(\mathrm{~m}_{\mathrm{c}}\right.$, $\left.\mathrm{C}_{2} \mathrm{CH}_{2} \mathrm{Ar}, 1 \mathrm{H}\right), 1.98\left(\mathrm{~m}_{\mathrm{c}}, \mathrm{CH}_{2} \mathrm{CH}_{2} \mathrm{Ar}, 1 \mathrm{H}\right), 2.08\left(\mathrm{~s}, \mathrm{Ar}-\mathrm{CH}_{3}, 3 \mathrm{H}\right), 2.14\left(\mathrm{~s}, \mathrm{Ar}-\mathrm{CH}_{3}, 3 \mathrm{H}\right), 2.18$ (s,

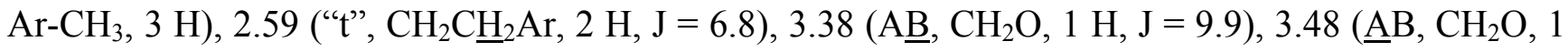
$\mathrm{H}, \mathrm{J}=9.9), 3.63\left(\mathrm{~s}, \mathrm{OCH}_{3}, 3 \mathrm{H}\right), 3.57$ and $3.58\left(2 \times \mathrm{q}, \mathrm{CH}_{2}-\mathrm{CH}_{3}, 2 \mathrm{H}, \mathrm{J}=7.0\right)$; IR (film): 2975, 2932, 2863, 1457, 1404, 1375, 1330, 1287, 1255, 1160, 1117, 1012, 929, $673 \mathrm{~cm}^{-1}$; MS: $278\left(\mathrm{M}^{\circ+}, 46\right), 219$ $\left(\mathrm{M}^{\circ+}-\mathrm{CH}_{2} \mathrm{OEt}, 100\right), 179\left(\mathrm{C}_{11} \mathrm{H}_{15} \mathrm{O}_{2}{ }^{+}\right.$, 72); Anal. Calcd. for $\mathrm{C}_{17} \mathrm{H}_{26} \mathrm{O}_{3}$ (278.39): C 73.35, H 9.41, Found C 72.36, H 9.40.

\section{Preparation of trichloromethanesulfinate 16}

$\mathrm{NEt}_{3}(2.65 \mathrm{~mL}, 23.0 \mathrm{mmol})$ was added to the magnetically stirred solution of alcohol $14(5.01 \mathrm{~g}, 10.0$ mmol) in $\mathrm{CH}_{2} \mathrm{Cl}_{2}(100 \mathrm{~mL})$, contained in a $250-\mathrm{mL}$ two-necked round-bottomed flask at room temperature. Subsequently, trichloromethanesulfinyl chloride $(2.78 \mathrm{~mL}, 24.0 \mathrm{mmol})$ was added dropwise (for TLC data see following procedure). The reaction mixture was diluted with $\mathrm{CH}_{2} \mathrm{Cl}_{2}$ and extracted twice with cooled $\left(0^{\circ} \mathrm{C}\right) 2 \mathrm{~N} \mathrm{H}_{2} \mathrm{SO}_{4}$. After separation of the phases, the organic layer was dried $\left(\mathrm{MgSO}_{4}\right)$ and evaporated to dryness (high vacuum). The $9.12 \mathrm{~g}$ of crude 16 were recrystallized from $10 \mathrm{~mL}$ pentane (ca. $-20^{\circ} \mathrm{C}$, overnight, washing of crystals with cold pentane), giving $7.65 \mathrm{~g}$ $(92 \%)$ of colourless crystals.

[(RS)-3,4-Dihydro-6-methoxy-2,5,7,8-tetramethyl-2H-1-benzopyran-2-yl]methyl (RS)-trichloromethanesulfinate (16). Mixture of diastereomers, ca. 1:1 (by NMR); m.p. 80-83 ${ }^{\circ} \mathrm{C}$; purity 99.3\% (SFC); ${ }^{1} \mathrm{H}-\mathrm{NMR}: \delta 1.33$ and $1.35\left(2 \times \mathrm{s}, \mathrm{C}_{\text {tert }}-\mathrm{CH}_{3}, 3 \mathrm{H}\right), 1.75-1.91\left(\mathrm{~m}, \mathrm{CH}_{2} \mathrm{CH}_{2} \mathrm{Ar}, 1 \mathrm{H}\right), 1.92-2.11(\mathrm{~m}$, $\left.\mathrm{CH}_{2} \mathrm{CH}_{2} \mathrm{Ar}, 1 \mathrm{H}\right), 2.10$ and $2.12\left(2 \times \mathrm{s}, \mathrm{Ar}_{-} \mathrm{CH}_{3}, 3 \mathrm{H}\right), 2.15\left(\mathrm{~s}, \mathrm{Ar}-\mathrm{CH}_{3}, 3 \mathrm{H}\right), 2.19\left(\mathrm{~s}, \mathrm{Ar}-\mathrm{CH}_{3}, 3 \mathrm{H}\right)$, 2.64 (" $\mathrm{t}$ ", $\left.\mathrm{CH}_{2} \mathrm{CH}_{2} \mathrm{Ar}, 2 \mathrm{H}, \mathrm{J}=6.8\right), 3.626$ and $3.632\left(2 \times \mathrm{s}, \mathrm{OCH}_{3}, 3 \mathrm{H}\right), 4.19\left(\mathrm{AB}, \mathrm{CH}_{2} \mathrm{OSO}, 1 \mathrm{H}\right.$ of diastereomer $1, \mathrm{~J}=11.0), 4.25\left(\mathrm{AB}, \mathrm{CH}_{2} \mathrm{OSO}, 1 \mathrm{H}\right.$ of diastereomer $\left.2, \mathrm{~J}=10.9\right), 4.32\left(\underline{\mathrm{AB}}, \mathrm{CH}_{2} \mathrm{OSO}, 1\right.$ $\mathrm{H}$ of diastereomer 2, J = 10.9), $4.38\left(\underline{\mathrm{AB}}, \mathrm{CH}_{2} \mathrm{OSO}, 1 \mathrm{H}\right.$ of diastereomer 1, J = 10.9); $\mathrm{IR}(\mathrm{KBr})$ : 2994 , 2939, 1459, 1403, 1304, 1254, 1187, 1115, 1088, 1061, 1041, 1009, 962, 925, 901, 827, 793, 736, 544

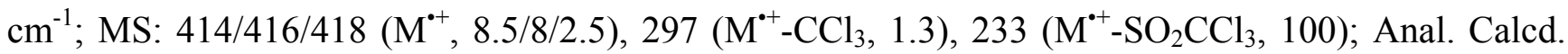


for $\mathrm{C}_{16} \mathrm{H}_{21} \mathrm{Cl}_{3} \mathrm{O}_{4} \mathrm{~S}$ (415.76): $\mathrm{C}$ 46.22, $\mathrm{H}$ 5.09, $\mathrm{Cl} 25.58, \mathrm{~S} 7.71$, Found $\mathrm{C} 46.31, \mathrm{H}$ 5.21, $\mathrm{Cl} 25.50, \mathrm{~S}$ 7.70 .

Oxidation of trichloromethanesulfinate $\mathbf{1 6}$ with potassium permanganate: Formation of sulfonates $\mathbf{1 5 g}$ and $\mathbf{1 5 i}$

In a $250-\mathrm{mL}$ round-bottomed flask, water $(10 \mathrm{~mL})$ was added to the solution of sulfinate $16(2.078 \mathrm{~g}$, $5.0 \mathrm{mmol})$ in pyridine $(50 \mathrm{~mL})$. This mixture was cooled to $0^{\circ} \mathrm{C}$, and $\mathrm{KMnO}_{4}(1.58 \mathrm{~g}, 10.0 \mathrm{mmol})$ was added at this temperature. TLC [EtOAc/ hexane $1: 3, \mathrm{R}_{\mathrm{f}}(\mathbf{1 6}) 0.47, \mathrm{R}_{\mathrm{f}}(\mathbf{1 5 g}) 0.42, \mathrm{R}_{\mathrm{f}}(\mathbf{1 5 i}) 0.36, \mathrm{R}_{\mathrm{f}}(\mathbf{1 4})$ $0.21]$ showed complete disappearance of starting sulfinate within 15 minutes. The reaction was quenched by addition of a soln. of $\mathrm{Na}_{2} \mathrm{~S}_{2} \mathrm{O}_{5}(3.80 \mathrm{~g}, 20.0 \mathrm{mmol})$ in water $(20 \mathrm{~mL})$ at $0^{\circ} \mathrm{C}$. After short stirring at this temperature, the resulting white suspension formed was filtered. The solid material filtered off was retained for further treatment, vide infra. The clear filtrate was evaporated to dryness. The red residue was taken up in a mixture of $\mathrm{Et}_{2} \mathrm{O}$ and water. The organic phase was washed with sat. $\mathrm{NaCl}$ soln., and the water phase was extracted with $\mathrm{Et}_{2} \mathrm{O}$. The combined organic phases were dried over $\mathrm{MgSO}_{4}$ and evaporated to dryness. The resulting $1.107 \mathrm{~g}$ of crude material were chromatographed (40 $\mathrm{g} \mathrm{SiO}_{2}$, EtOAc/hexane 1:4, 10-mL fractions) to give a first fraction of $671 \mathrm{mg}$ containing $\mathbf{1 5 g}$ and 15i, and $202 \mathrm{mg}$ crystalline alcohol $14(16 \%)$. The mixture obtained from the first fraction was

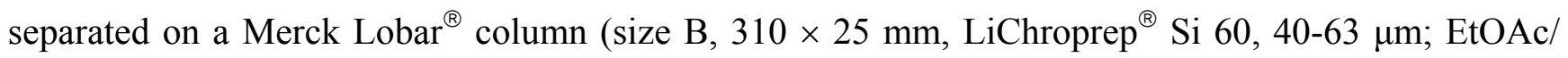
hexane 1:19, 10-mL fractions): Successively, $301 \mathrm{mg}(14 \%)$ trichlorosulfonate $\mathbf{1 5 g}$ and $305 \mathrm{mg}(14 \%)$ dichlorosulfonate 15i were eluted and obtained as colourless crystals after distilling off the solvent. The $301 \mathrm{mg}$ of $\mathbf{1 5 g}$ were stirred up with hexane $(2 \mathrm{~mL})$ under ultrasonication, filtered off, and dried under high vacuum to give $282 \mathrm{mg}(13 \%)$ colourless $\mathbf{1 5 g}$, which was used for obtaining the characterization data. The filtration sludge from the first filtration (after quenching of the reaction by addition of hydrogensulfite soln., see above) was stirred up with water and filtered. The $1.34 \mathrm{~g}$ of undissolved solids thus obtained were taken up in warm $2 \mathrm{~N} \mathrm{HCl}$ (odour of $\mathrm{SO}_{2}$ ) and extracted with ethyl acetate. From this organic phase an additional $52 \mathrm{mg}$ (4\%) of alcohol 14 were obtained after evaporation under reduced pressure.

[(RS)-3,4-Dihydro-6-methoxy-2,5,7,8-tetramethyl-2H-1-benzopyran-2-yl]methyl trichloromethanesulfonate (15g). M.p. $104-105^{\circ} \mathrm{C}$; purity 100\% (SFC); ${ }^{1} \mathrm{H}-\mathrm{NMR}: \delta 1.39\left(\mathrm{~s}, \mathrm{C}_{\text {tert }}-\mathrm{CH}_{3}, 3 \mathrm{H}\right), 1.86\left(\mathrm{~m}_{\mathrm{c}}\right.$, $\left.\mathrm{C}_{2} \mathrm{CH}_{2} \mathrm{Ar}, 1 \mathrm{H}\right), 2.02\left(\mathrm{~m}_{\mathrm{c}}, \mathrm{CH}_{2} \mathrm{CH}_{2} \mathrm{Ar}, 1 \mathrm{H}\right), 2.10$ (s, Ar- $\left.\mathrm{CH}_{3}, 3 \mathrm{H}\right), 2.15$ (s, Ar- $\left.\mathrm{CH}_{3}, 3 \mathrm{H}\right), 2.19$ (s, Ar$\mathrm{CH}_{3}, 3 \mathrm{H}$ ), 2.66 ("t", $\left.\mathrm{CH}_{2} \mathrm{CH}_{2} \mathrm{Ar}, 2 \mathrm{H}, \mathrm{J}=6.9\right), 3.63\left(\mathrm{~s}, \mathrm{OCH}_{3}, 3 \mathrm{H}\right), 4.54\left(\mathrm{AB}, \mathrm{CH}_{2} \mathrm{OSO}_{2}, 1 \mathrm{H}, \mathrm{J}=\right.$ 10.15), 4.60 ( $\left.\underline{\mathrm{AB}}, \mathrm{CH}_{2} \mathrm{OSO}_{2}, 1 \mathrm{H}, \mathrm{J}=10.15\right)$; IR (KBr): 2993, 2933, 1463, 1398, 1385, 1296, 1256, 1193, 1177, 1119, 1089, 1062, 1012, 968, 907, 866, 810, 594, 572, $515 \mathrm{~cm}^{-1}$; MS: 430/432/434 $\left(\mathrm{M}^{++}\right.$, 39/39/17), 415/417/419 (M++-15, 5/5/2), $232\left(\mathrm{M}^{\bullet+}-\mathrm{HOSO}_{2} \mathrm{CCl}_{3}, 19\right), 219\left(\mathrm{M}^{\bullet+}-\mathrm{H}_{2} \mathrm{COSO}_{2} \mathrm{CCl}_{3}, 47\right)$, 217 (61), $179\left(\mathrm{C}_{11} \mathrm{H}_{15} \mathrm{O}_{2}{ }^{++}, 100\right)$; Anal. Calcd. for $\mathrm{C}_{16} \mathrm{H}_{21} \mathrm{Cl}_{3} \mathrm{O}_{5} \mathrm{~S}$ (431.76): C 44.51, $\mathrm{H} 4.90, \mathrm{Cl} 24.63, \mathrm{~S}$ 7.43, Found C 44.69, H 5.00, Cl 24.62, S 7.28. 
[(RS)-3,4-Dihydro-6-methoxy-2,5,7,8-tetramethyl-2H-1-benzopyran-2-yl]methyl dichloromethanesulfonate (15i ). M.p. 84-85 ${ }^{\circ} \mathrm{C}$; purity $100 \%$ (SFC); ${ }^{1} \mathrm{H}-\mathrm{NMR}: \delta 1.34\left(\mathrm{~s}, \mathrm{C}_{\text {tert }}-\mathrm{CH}_{3}, 3 \mathrm{H}\right), 1.83\left(\mathrm{~m}_{\mathrm{c}}\right.$, $\left.\mathrm{C}_{2} \mathrm{CH}_{2} \mathrm{Ar}, 1 \mathrm{H}\right), 2.03\left(\mathrm{~m}_{\mathrm{c}}, \mathrm{C}_{2} \mathrm{CH}_{2} \mathrm{Ar}, 1 \mathrm{H}\right), 2.09$ (s, Ar- $\left.\mathrm{CH}_{3}, 3 \mathrm{H}\right), 2.15$ (s, $\mathrm{Ar}-\mathrm{CH}_{3}, 3 \mathrm{H}$ ), 2.19 (s, Ar$\mathrm{CH}_{3}, 3 \mathrm{H}$ ), 2.66 ("t", $\left.\mathrm{CH}_{2} \mathrm{C}_{2} \mathrm{Ar}, 2 \mathrm{H}, \mathrm{J}=6.7\right), 3.63\left(\mathrm{~s}, \mathrm{OCH}_{3}, 3 \mathrm{H}\right), 4.42\left(\mathrm{~A} \underline{\mathrm{B}}, \mathrm{CH}_{2} \mathrm{OSO}_{2}, 1 \mathrm{H}, \mathrm{J}=\right.$ 10.5), $4.55\left(\underline{\mathrm{AB}}, \mathrm{CH}_{2} \mathrm{OSO}_{2}, 1 \mathrm{H}, \mathrm{J}=10.5\right), 6.41$ (s, $\left.\mathrm{CHCl}_{2}, 1 \mathrm{H}\right)$; IR (KBr): 2992, 2940, 1467, 1402, 1370, 1304, 1258, 1193, 1174, 1120, 1094, 1062, 1004, 967, 832, 802, 781, 705, 557, $514 \mathrm{~cm}^{-1}$; MS: 396/398/400 ( $\left.\mathrm{M}^{\circ+}, 51 / 36 / 8\right), 381 / 383 / 385\left(\mathrm{M}^{\circ+}-15,6 / 4 / 1\right), 232\left(\mathrm{M}^{*+}-\mathrm{HOSO}_{2} \mathrm{CHCl}_{2}, 10\right), 219\left(\mathrm{M}^{{ }^{+}-}\right.$ $\left.\mathrm{H}_{2} \mathrm{COSO}_{2} \mathrm{CHCl}_{2}, 30\right), 217$ (55), $179\left(\mathrm{C}_{11} \mathrm{H}_{15} \mathrm{O}_{2}{ }^{\circ+}, 100\right)$; Anal. Calcd. for $\mathrm{C}_{16} \mathrm{H}_{22} \mathrm{Cl}_{2} \mathrm{O}_{5} \mathrm{~S}$ (397.31): $\mathrm{C}$ 48.37, H 5.58, Cl 17.85, S 8.07, Found C 48.47, H 5.56, Cl 17.76, S 8.00.

\section{Reaction of alcohol $\mathbf{1 4}$ with sulfuryl chloride fluoride: Formation of chlorosulfonate $\mathbf{1 5 h}$}

$\mathrm{NEt}_{3}(2.0 \mathrm{~mL}, 14.37 \mathrm{mmol})$ was added to a solution of alcohol $14(3.00 \mathrm{~g}, 12.0 \mathrm{mmol})$ in $\mathrm{CH}_{2} \mathrm{Cl}_{2}(100$ $\mathrm{mL})$ at $-78^{\circ} \mathrm{C}$. This solution was then added dropwise over $1 \mathrm{~h}$ to a magnetically stirred solution of $\mathrm{SO}_{2} \mathrm{ClF}(3.053 \mathrm{~g}, 25.76 \mathrm{mmol})$ in $\mathrm{CH}_{2} \mathrm{Cl}_{2}(20 \mathrm{~mL})$ at $-78^{\circ} \mathrm{C}$ [TLC: EtOAc/ hexane 1:3, $\mathrm{R}_{\mathrm{f}}(\mathbf{1 4}) 0.22$, $\mathrm{R}_{\mathrm{f}}(\mathbf{1 5 h})$ 0.44]. The reaction was quenched by addition of water $(20 \mathrm{~mL})$ at this temperature. The mixture was poured onto dil. $\mathrm{H}_{2} \mathrm{SO}_{4}(100 \mathrm{~mL})$ and the phases were separated. The organic phase was washed with water, dried $\left(\mathrm{MgSO}_{4}\right)$, and evaporated under reduced pressure at $20^{\circ} \mathrm{C}$. The crude product (4.2 g) was dissolved in $\mathrm{Et}_{2} \mathrm{O}$ and concentrated (rotary evaporator, room temp.) to yield three crops of colourless crystals, for a combined total of $3.03 \mathrm{~g}(72 \%)$.

rac-(3,4-Dihydro-6-methoxy-2,5,7,8-tetramethyl-2H-1-benzopyran-2-yl)methyl chlorosulfonate (15h) M.p. $109-110^{\circ} \mathrm{C}$; purity $99.1 \%$ (SFC at $60^{\circ} \mathrm{C}$ ), $95.5 \%$ (SFC at $100^{\circ} \mathrm{C}$; indicating thermal decomposition during analysis [13]); ${ }^{1} \mathrm{H}-\mathrm{NMR}: \delta 1.39\left(\mathrm{~s}, \mathrm{C}_{\text {tert }}-\mathrm{CH}_{3}, 3 \mathrm{H}\right), 1.87\left(\mathrm{~m}_{\mathrm{c}}, \mathrm{C}_{2} \mathrm{CH}_{2} \mathrm{Ar}, 1 \mathrm{H}\right)$, $2.01\left(\mathrm{~m}_{\mathrm{c}}, \mathrm{CH}_{2} \mathrm{CH}_{2} \mathrm{Ar}, 1 \mathrm{H}\right), 2.08$ (s, $\left.\mathrm{Ar}-\mathrm{CH}_{3}, 3 \mathrm{H}\right), 2.15$ (s, Ar- $\left.\mathrm{CH}_{3}, 3 \mathrm{H}\right), 2.19$ (s, $\left.\mathrm{Ar}-\mathrm{CH}_{3}, 3 \mathrm{H}\right), 2.66$ ("t", $\left.\mathrm{CH}_{2} \mathrm{C}_{2} \mathrm{Ar}, 2 \mathrm{H}, \mathrm{J}=6.8\right), 3.63\left(\mathrm{~s}, \mathrm{OCH}_{3}, 3 \mathrm{H}\right), 4.40\left(\mathrm{AB}, \mathrm{CH}_{2} \mathrm{OSO}_{2}, 1 \mathrm{H}, \mathrm{J}=9.7\right), 4.47$ ( $\underline{\mathrm{AB}}$, $\left.\mathrm{CH}_{2} \mathrm{OSO}_{2}, 1 \mathrm{H}, \mathrm{J}=9.7\right)$; IR (KBr): 2982, 2937, 1462, 1402, 1385, 1295, 1256, 1190, 1172, 1121 ,

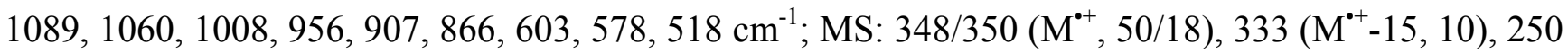
$\left(\mathrm{M}^{\circ+}-\mathrm{SO}_{2} \mathrm{Cl}+\mathrm{H}, 24\right), 219\left(\mathrm{M}^{\circ+}-\mathrm{H}_{2} \mathrm{COSO}_{2} \mathrm{Cl}, 34\right), 217$ (40), $179\left(\mathrm{C}_{11} \mathrm{H}_{15} \mathrm{O}_{2}{ }^{\circ+}, 100\right)$; Anal. Calcd. for $\mathrm{C}_{15} \mathrm{H}_{21} \mathrm{ClO}_{5} \mathrm{~S}$ (348.85): C 51.65, H 6.07, $\mathrm{Cl} 10.16, \mathrm{~S} 9.19$, Found C 51.49, H 6.36, Cl 10.28, S 9.09, F 0.00 .

Reaction of alcohol $\mathbf{1 4}$ with trichloromethanesulfonyl chloride: Formation of chlorosulfonate $\mathbf{1 5 h}$ and bissulfonate $\mathbf{1 8}$

2,6-Lutidine $(2.79 \mathrm{~mL}, 24.0 \mathrm{mmol})$ was added to a solution of alcohol $14(5.01 \mathrm{~g}, 10.0 \mathrm{mmol})$ in $\mathrm{CH}_{2} \mathrm{Cl}_{2}(100 \mathrm{~mL})$. To this solution trichloromethanesulfonyl chloride $(5.01 \mathrm{~g}, 3.0 \mathrm{mmol})$ was added at room temp. while stirring. After $20 \mathrm{~min}$. at room temp. and $75 \mathrm{~h}$ at reflux only starting material could be detected by TLC, therefore the solvent was replaced by adding THF $(100 \mathrm{~mL})$ and subsequently 
distilling off $\mathrm{CH}_{2} \mathrm{Cl}_{2}$ and the mixture was further refluxed (bath temp. $80^{\circ} \mathrm{C}$ ) for $18 \mathrm{~h}$ [TLC: EtOAc/ hexane $1: 3, \mathrm{R}_{\mathrm{f}}(\mathbf{1 4}) \mathbf{0 . 2 4}, \mathrm{R}_{\mathrm{f}}(\mathbf{1 5 h}) \mathbf{0 . 4 4}, \mathrm{R}_{\mathrm{f}}(\mathbf{1 8})$ 0.38]. The resulting complex reaction mixture was partitioned between $\mathrm{Et}_{2} \mathrm{O}$ and water $(200 \mathrm{~mL}$ each). The phases were separated, and the water phase was extracted with additional $\mathrm{Et}_{2} \mathrm{O}(200 \mathrm{~mL})$. The combined organic phases were washed with $2 \mathrm{~N}$ $\mathrm{H}_{2} \mathrm{SO}_{4}(100 \mathrm{~mL})$, dried over $\mathrm{MgSO}_{4}$ and evaporated to dryness. The resulting $5.98 \mathrm{~g}$ of crude brown oil was subjected to chromatography $\left(60 \mathrm{~g} \mathrm{SiO}_{2}, \mathrm{EtOAc/hexane} \mathrm{1:9)} \mathrm{from} \mathrm{which} \mathrm{compounds} 15 \mathrm{~h}\right.$ (643 mg colourless crystals, 36\%, after recryst. from pentane) and $\mathbf{1 8}$ (108 mg colourless crystals, 8\%) were collected.

Sulfuric acid bis[[(R/S)-3,4-dihydro-6-methoxy-2,5,7,8-tetramethyl-2H-1-benzopyran-2-yl]methyl] diester (18). Mixture of diastereomers, not pure; ${ }^{1} \mathrm{H}-\mathrm{NMR}$ : $\delta$ 1.26-1.32 (several s, $\mathrm{C}_{\text {tert }}-\mathrm{CH}_{3}, 6 \mathrm{H}$ ), 1.7 2.1 (m, $\underline{\mathrm{CH}}_{2} \mathrm{CH}_{2} \mathrm{Ar}, 4 \mathrm{H}$ ), 2.04-2.25 (several s, Ar- $\mathrm{CH}_{3}, 18 \mathrm{H}$ ), 2.61 ("t", $\mathrm{CH}_{2} \mathrm{CH}_{2} \mathrm{Ar}, 4 \mathrm{H}$ ), 3.61-3.64 (several s, $\left.\mathrm{OCH}_{3}, 6 \mathrm{H}\right), 4.1-4.3(\mathrm{~m}, 4 \mathrm{H})$; MS: $562\left(\mathrm{M}^{\circ+}, 5\right), 498\left(\mathrm{M}^{\circ+}-\mathrm{SO}_{2}, 2\right), 482\left(\mathrm{M}^{\circ+}-\mathrm{SO}_{3}, 0.1\right), 330$ (20), 250 (35), 233 (40), 219 (73), $217(20), 179\left(\mathrm{C}_{11} \mathrm{H}_{15} \mathrm{O}_{2}{ }^{*+}, 100\right)$.

\section{References and Notes}

1. Noyce, D.S.; Virgilio, J.A. The Synthesis and Solvolysis of 1-Phenylethyl Disubstituted Phosphinates, J. Org. Chem. 1972, 37, 2643-2647.

2. Stang, P.J.; Hanack, M.; Subramanian, L.R. Perfluoroalkanesulfonic Esters: Methods of Preparation and Applications in Organic Chemistry, Synthesis 1982, 85-126, and cit. lit.

3. Crossland, R.K.; Wells, W.E.; Shiner Jr., V.J. Sulfonate Leaving Groups, Structure and Reactivity. 2,2,2-Trifluoroethanesulfonate, J. Am. Chem. Soc. 1971, 93, 4217-4219.

4. Netscher, Th.; Schwesinger, R.; Trupp, B.; Prinzbach, H. tert-Butyl- and 2,2,2-Trifluoro-1,1Diphenylethane-Sulfonates - Hindrance of S-O-Scission in $\mathrm{S}_{\mathrm{N}} 2$-Substitution Reactions, Tetrahedron Lett. 1987, 28, 2115-2118.

5. Netscher, Th.; Prinzbach, H. Sterically Crowded Sulfonate Esters: Novel Leaving Groups with Hindered S-O Cleavage, Synthesis 1987, 683-688.

6. Netscher, Th. Application of Sterically Crowded Alkyl Sulfonates: $\mathrm{S}_{\mathrm{N}} 2$-Substitution in the Diacetone Glucose System, Tetrahedron Lett. 1988, 29, 455-458.

7. On the way to reagents iii and vi $(n=0,1)$ containing an activating $\mathrm{CF}_{3}$ group, carboxylic acids ii \{accessible from $\beta$-bromoisobutyric acid (i) by xanthogenate substitution, saponification, and benzylation of the thiol [8,9]\} and $\mathbf{v}$ \{from $(+)$-camphene (iv) by oxidation [10] and subsequent thiobenzylation $[11,12]\}$ could not be fluorinated by $\mathrm{SF}_{4}$, presumably due to steric crowding. The fluorination experiments were conducted in the laboratory of Professor Haas at the University of Bochum, Germany. 

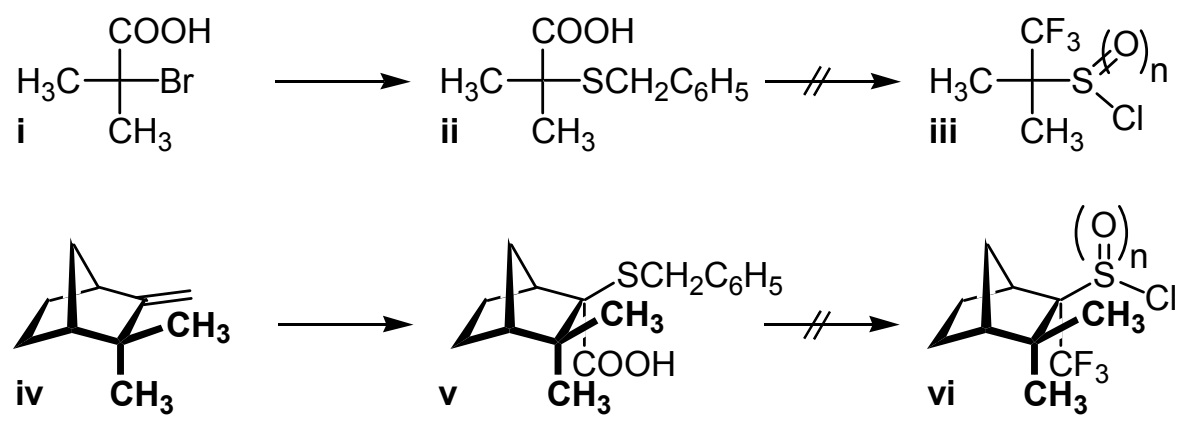

8. Biilmann, E. Studien über organische Thiosäuren II, Liebigs Ann. Chem. 1906, 348, 120-132.

9. Iskander, Y.; Tewfik, R. The Carbon-Sulphur Fission in Thio-ethers. Part I. The Retarding Influence of $\alpha$-Methyl Groups and of the Length of the Acid Chain on the Alkaline Hydrolysis of (2-Ketoalkylthio)- and (p-Nitrotriphenylmethylthio)-acetic Acids, J. Chem. Soc. 1951, 2050-2053.

10. Buchbauer, G.; Vitek, R.; Hirsch, M.C.; Kurz, Ch.; Cech, B.; Vas, E.M. Oxidationsreaktionen am 1-(3,3-Dimethyl-5-norbornen-2-yl)ethanon und ein neuer Zugang zu endo-konfigurierten Isocamphanderivaten, Monatsh. Chem. 1982, 113, 1433-1450.

11. Review: Trost, B.M. $\alpha$-Sulfenylated Carbonyl Compounds in Organic Synthesis, Chem. Rev. 1978, 78, 363-382.

12. Netscher, Th. Dianhydroinosite als Bausteine für neuartige Komplexliganden - Entwicklung sterisch gehinderter Abgangsgruppen, Dissertation, Universität Freiburg i.Br., Germany, 1986.

13. Walther, W.; Netscher, Th. Open-Tubular Column Supercritical Fluid Chromatography: Analysis of Thermolabile Intermediates Useful in Natural Product Synthesis, J. Chromatogr. Sci. 1994, 32 , 418-425.

14. Netscher, Th.; Bohrer, P. Formation of Sulfinate Esters in the Synthesis of Triflates, Tetrahedron Lett. 1996, 37, 8359-8362.

15. (a) Hall, L.D.; Miller, D.C. Fluorinated Sulphonic Esters of Sugars: Their Synthesis and Reactions with Pyridine, Carbohydr. Res. 1976, 47, 299-305; (b) Ambrose, M.G.; Binkley, R.W. Synthesis of Deoxyhalogeno Sugars. Reaction of Halide Ions with 1,2,3,4-Tetra- $O$-acetyl-6- $O$-[(trifluoromethyl)sulfonyl]-a-D-glucopyranose, J. Org. Chem. 1983, 48, 674-677; (c) Al-Abed, Y.; Naz, N.; Khan, Kh.M.; Voelter, W. Pyridinium-Ionen in Nachbarschaft zu Oxiranringen: nützliche Zwischenstufen zur stereospezifischen Synthese von $\beta$-Hydroxyketonen, Angew. Chem. 1996, 108, 581-582; Angew. Chem. Int. Ed. Engl. 1996, 35, 523.

16. Netscher, Th. Stereoisomers of Tocopherols - Syntheses and Analytics, Chimia 1996, 50, 563567 , and references cited therein.

17. Esters from trifluoro- and hexafluoro-2-propanol and sulfonyl fluoride $\left(\mathrm{CH}_{2} \mathrm{Cl}_{2}, \mathrm{NEt}_{3},-40^{\circ} \mathrm{C}\right)$ : Hanack, M.; Ullmann, J. Facile Synthesis of Trifluoro- and Hexafluoroisopropyl Halides, J. Org. Chem. 1989, 54, 1432-1435. Aryl esters: Rottländer, M.; Knochel, P. Palladium-Catalyzed CrossCoupling with Aryl Nonaflates: A Practical Alternative to Aryl Triflates, J. Org. Chem. 1998, 63, 203-208, and literature cited therein. 
18. Subramanian, L.R.; Hanack, M. Vinyl-Kationen, V. Kinetik und Solvolyse von Nonafluorbutansulfonaten ("Nonaflate"), Chem. Ber. 1972, 105, 1465-1470.

19. Jäger, H. Sulfonsäure-anhydride, In Houben-Weyl, Methoden der Organischen Chemie, Bd. E11 (D. Klamann, Ed.), Thieme: Stuttgart 1985; pp. 1078 and following.

20. Cremlyn, R.J. An Introduction to Organosulfur Chemistry, John Wiley \& Sons: Chichester 1996, pp. 29-30 (Chapt. 3, Structure-Chemical Relationships in Organosulfur Compounds) and p. 106 (Chapt. 7, Sulfinic Acids, Sulfonic Acids and Derivatives; Sulfenes).

21. (a) Steinmann, M.; Topliss, J.G.; Alekel, R.; Wong, Y.-Sh.; York, E.E. 1-Polyfluoroalkylbenzodiazepines. 1, J. Med. Chem. 1973, 16, 1354-1360; (b) Topliss J.G. (Schering Corp.), 1Polyfluoroalkyl 2-oxo-1,3-dihydro-2H-1,4-benzodiazepines, US 3,429,874, 25 Feb 1969 [Chem. Abstr. 1969, 71, 3415r].

22. Czerkawski, J.W.; Breckenridge, G. New inhibitors of methane production by rumen microorganisms. Development and testing of inhibitors in vitro, Br. J. Nutr. 1975, 34, 429-446.

23. Drahowzal F.A., In Organic Sulfur Compounds, Vol. 1, (N. Kharasch, Ed.), Pergamon Press: Oxford 1961, p. 371-372; a reference pointing to an exception (amyl ester) is misleading. In ref. 22 , the preparation of the ethyl ester is mentioned, but without proof of structure by spectroscopic data.

24. Example vii in ref. 12:

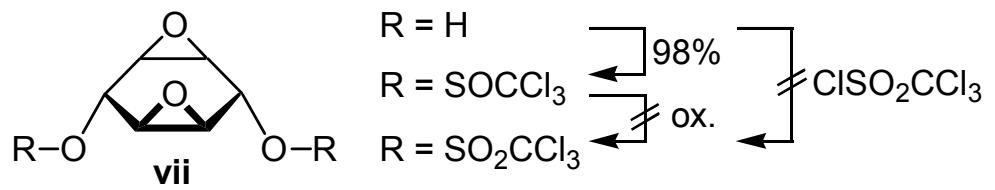

25. Schöllkopf, U.; Hilbert, P. Dichlorcarben aus Trichlormethan-sulfinsäuremethylester und Trichlormethan-sulfonylchlorid, Angew. Chem. 1962, 74, 431-432; Angew. Chem. Int. Ed. Engl. 1962, $1,401$.

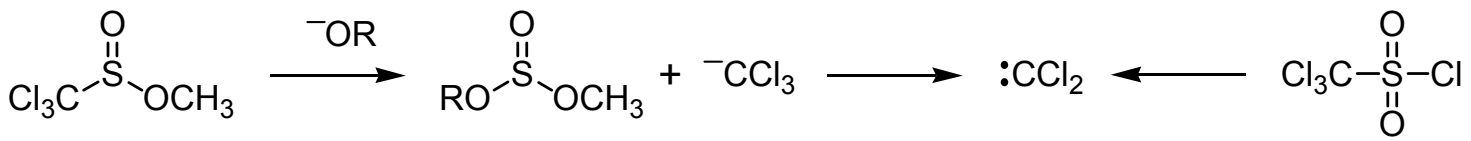

26. Braverman, S.; Duar, Y. Highly Reactive Sulfinates - The Synthesis and Solvolysis of Benzyl Trichloromethanesulfinates, Tetrahedron Lett. 1975, 343-346.

27. Oxidation of sulfur compounds: Schöberl, A.; Wagner, A. Herstellung von Sulfoxyden, in Houben-Weyl, Methoden der Organischen Chemie, Bd. 9 (E. Müller, Ed.), pp. 211-221, Thieme: Stuttgart 1955. For additional references see ref. 12.

28. Šilhánek, J.; Zbirovský, M. The Alkaline Hydrolysis of Trichloromethanesulfenyl Chloride - A Simple Preparation of Dichloromethanesufinates, Int. J. Sulfur Chem. 1973, 8, 423-425. 
29. (a) Grossert, J.S.; Hardstaff, W.R.; Langler, R.F. Oxidative Chlorination of $\alpha$-Halogenosulphides as a Synthetic Route to $\alpha$-Halogenosulphoxides, Sulphinyl Chlorides, and Sulphonyl Chlorides, $J$. Chem. Soc., Chem. Commun. 1973, 50; (b) Grossert, J.S.; Langler, R.F. The sulfohaloform reaction. The stepwise conversion of dialkyl sulfides into alkanesulfonyl chlorides, Can. J. Chem. 1977, 55, 407-420.

30. Langler, R.F.; LeBlanc, L.M.; Smith, L.L. Sulfonyl Esters. IV The Preparation of Aryl Dichloromethane- and Trichloromethane-sulfonate Esters, Aust. J. Chem. 1993, 46, 1085-1091.

31. (a) Shimizu, T.; Ohzeki, T.; Hiramoto, K.; Hori, N.; Nakata, T. Chloromethansulfonate as an Efficient Leaving Group: Rearrangement of the Carbon-Carbon Bond and Conversion of Alcohols into Azides and Nitriles, Synthesis 1999, 1373-1385; (b) Hori, N.; Nagasawa, K.; Shimizu, T.; Nakata, T. Efficient Synthesis of 2,3-trans-Tetrahydropyrans and Oxepanes: Rearrangement-Ring Expansion of Cyclic Ethers Having a Chloromethanesulfonate, Tetrahedron Lett. 1999, 40, 2145 2148; (c) Sakamoto, Y.; Tamegai, K.; Nakata, T. Stereoselective Ring Expansion via Bicyclooxonium Ion. A Novel Approach to Oxocanes, Org. Lett. 2002, 4, 675-678; (d) Hayashi, N.; Noguchi, H.; Tsuboi, S. Transformation of cis-Epoxy Compound to cis-2,3-Disubstituted Oxane and Investigation on Propagation Step in the Ring-Expansion Reactions of cis,transDiepoxy Systems, Tetrahedron 2000, 56, 7123-7137; (e) Matsuo, G.; Hori, N.; Matsukura, H.; Nakata, T. Synthetic studies on brevetoxin-B. Part 2: Stereoselective synthesis of the EFG-ring system, Tetrahedron Lett. 2000, 41, 7677-7680; (f) Hiranuma, S.; Shimizu, T.; Nakata, T.; Kajimoto, T.; Wong, Ch.-H. Synthesis and Inhibition Analysis of Five-Membered Homoazasugars from D-Arabinofuranose via an SN2 Reaction of the Chloromethylsulfonate, Tetrahedron Lett. 1995, 36, 8247-8250; (g) Shimizu, T.; Hiranuma, S.; Nakata, T. Efficient Method for Inversion of Secondary Alcohols by Reaction of Chloromethanesulfonates with Cesium Acetate, Tetrahedron Lett. 1996, 37, 6145-6148.

32. Goldwhite, H.; Gibson, M.S.; Harris, C. Free Radical Addition Reactions - I. The Reaction of Tri-, Di- and Mono-Chloromethanesulphonyl Chlorides with Alkenes, Tetrahedron 1964, 20, 1613-1624. On esterification of sterically hindered alcohols with methanesulfonyl chloride in presence of a base, chlorinated sulfinate esters were found as by-products: Srikrishna, A.; Gharpure, S.J. Novel Formation of Chloromethanesulfinates in the Methanesulfonylation Reaction of Hindered Alcohols, Synlett 2000, 1354-1356.

33. Ahmed, M.G.; Alder, R.W.; James, G.H.; Sinnott, M.L.; Whiting, M.C. Alkylations with Methyl and Ethyl Fluorosulphonates, Chem. Commun. 1968, 1533-1534.

34. Review: Szarek, W.A. Deoxyhalogeno Sugars, Adv. Carbohydr. Chem. Biochem. 1973, 28, 225, and lit. cited therein.

35. Esterification of fluorinated alcohols: (a) Kinkead, S.A.; Kumar, R.C.; Shreeve, J.M. Reactions of Polyfluoroalkyl Fluorosulfates with Nucleophiles: An Unusual Substitution at the Sulfur-Fluorine Bond, J. Am. Chem. Soc. 1984, 106, 7496-7500; (b) Kumar, R.C.; Kinkead, S.A.; Shreeve, J.M. Reactions of Bis(2,2,2-trifluoroethyl) Sulfite, Bis(hexafluoroisopropyl) Sulfite, and Diethyl Sulfite with Chlorine Fluoride: Evidence of an Arbuzov Rearrangement, Inorg. Chem. 1984, 23, 
3112-3114. Esterification of phenols: Cramer, R.; Coffman, D.D. New Syntheses of Aryl Fluorides and Aryl Fluorosulfonates from Oxyfluorides of Sulfur, J. Org. Chem. 1961, 26, 41644165.

36. We thank Professor Jack Baldwin, Oxford University, for fruitful discussions.

37. Sinn, F.; Schimmelschmidt, K. Methoden zur Herstellung und Umwandlung von Chlorsulfonsäureestern, in Houben-Weyl, Methoden der Organischen Chemie, Bd. VI/2 (E. Müller, Ed.); Thieme: Stuttgart, 1963; pp. 466-469. Recent example: Koseki, Y.; Sato, H.; Watanabe, Y.; Nagasaka, T. A Formal Total Synthesis of $( \pm)$-Cephalotaxine Using Sequential N-Acyliminium Ion Reactions, Org. Lett. 2002, 4, 885-888.

38. (a) Hanessian, S.; Vatèle, J.-M. Design and Reactivity of Organic Functional Groups: Imidazolylsulfonate (Imidazylate) - An Efficient and Versatile Leaving Group, Tetrahedron Lett. 1981, 22, 3579-3582; (b) Vatèle, J.-M.; Hanessian, S. Design and Reactivity of Organic Functional Groups - Preparation and Nucleophilic Displacement Reactions of Imidazole-1sulfonates (Imidazylates), Tetrahedron 1996, 52, 10557-10568.

39. Yamaguchi, T.; Hattori, K.; Nakao, K.; Tamaki, K. Preparation of Methyl 2-Arylpropanoates by the Reaction of 2-Hydroxypropiophenone Dimethyl Acetals with Sulfuryl Chloride in the Presence of an Amide or a Weak Base, Bull. Chem. Soc. Jpn. 1987, 60, 4015-4018.

40. Kongpricha, S.; Preusse, W.C.; Schwarer, R. 32. Disulfuryl Fluoride, Inorg. Synth. 1968, 11, 151155.

Sample Availability: Available from the authors.

(C) 2002 by MDPI (http://www.mdpi.org). Reproduction is permitted for noncommercial purposes. 